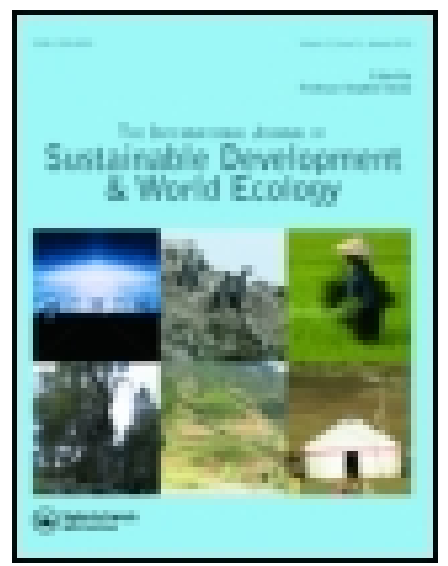

International J ournal of Sustainable Development \& World Ecology

Publication details, including instructions for authors and subscription information: http:// www. tandfonline.com/loi/tsdw20

\title{
Carbon discharge through municipal solid waste in Haikou, China
}

Tingwen Luo, Zhiyun Ouyang, Xiaoke Wang, Weifeng Li \& Weihua Xu Published online: 24 Nov 2009.

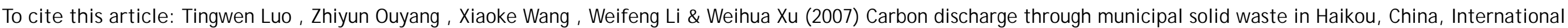
J ournal of Sustainable Development \& World Ecology, 14:5, 511-519, DOI: 10.1080/ 13504500709469750

To link to this article: http:// dx. doi.org/ 10.1080/13504500709469750

\section{PLEASE SCROLL DOWN FOR ARTICLE}

Taylor \& Francis makes every effort to ensure the accuracy of all the information (the "Content") contained in the publications on our platform. However Taylor \& Francis, our agents, and our licensors make no representations or warranties whatsoever as to the accuracy, completeness, or suitability for any

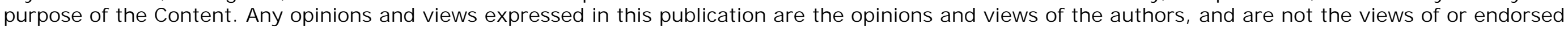

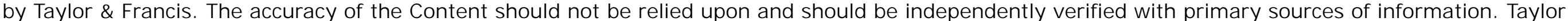

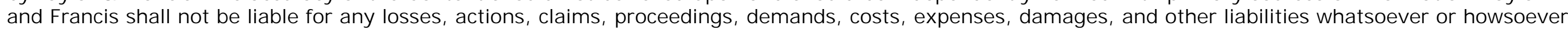
caused arising directly or indirectly in connection with, in relation to or arising out of the use of the Content.

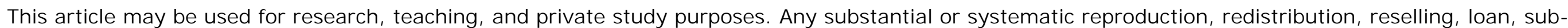
licensing, systematic supply, or distribution in any form to anyone is expressly forbidden. Terms \& Conditions of access and use can be found at http:// www.tandfonline.com/page/terms-and-conditions 


\title{
Carbon discharge through municipal solid waste in Haikou, China
}

Tingwen Luo, Zhiyun Ouyang, Xiaoke Wang, Weifeng Li and Weihua Xu

State Key Lab of Systems Ecology, Research Center for Eco-Environmental Sciences, Chinese Academy of Sciences, Beijing, China

Key words: Municipal solid waste, carbon discharge, carbon metabolism, urban carbon flow, urban ecosystems

\begin{abstract}
SUMMARY
With rapid urban development, municipal solid waste (MSW) has become a pressing issue. Estimation of carbon discharge through municipal solid waste provides a way to assess environmental load of solid waste from the viewpoint of the carbon cycle. With few studies on carbon flow in urban ecosystems, this research contributes to urban carbon research and provides insights into human impacts on the carbon cycle. Based on a comprehensive fieldwork investigation of a typical Chinese tourist city - Haikou City, Hainan Island - the characteristics of MSW carbon discharge and human activities that influenced it were analysed. The results indicated that, in 2001, the total carbon discharge from $261.9 \mathrm{Gg}$ of MSW was $105.1 \mathrm{GgC}$ per year, and $174.6 \mathrm{kgC}$ per capita per annum. Carbon is discharged in the form of food scraps (24\%), plastics (20\%), wood (17\%), fabrics (14\%), paper $(13 \%)$, and dust and stone $(12 \%)$. If landfill received all the waste, $4.7 \%$ of MSW carbon would be transformed into methane, with a value of $4.9 \mathrm{GgC}$. Between 1991 and 1999, Haikou's per capita MSW carbon discharge increased by $59.9 \%$, and total MSW carbon discharge increased by $124.9 \%$. MSW carbon discharge in Haikou is significantly affected by the growth of residential expenditure and urbanisation. Local characteristics of tourism also influence Haikou's MSW carbon discharge, not only in terms of its yearly variation, but also its monthly variation. Integrating data on carbon discharge with carbon consumption will provide a systematic view of the carbon metabolism in urban ecosystems, and further insights into the generation of urban environmental pollution.
\end{abstract}

\section{INTRODUCTION}

For the past 150 years, urbanisation has proved to be a major global trend with significant impacts on society and the environment. Moreover, this trend will continue, and it is predicted that half of the world's population will live in urban areas by 2007 and three-quarters by 2030 (United Nations Population Division 2002; Gelbard et al. 1999). For the first time in history, more people are living in cities than outside them (Crane and Kinzig 2005). The

prosperity of cities drives changes in the economy, education, employment, criminal justice, transportation and housing (Crane and Kinzig 2005; Moore et al. 2003; Vlahov and Galea 2003; Satterthwaite 2000; Lawrence 1999). However, rapid and uncontrolled urbanisation growth degrades the urban environment, places serious stress on natural resources and results in many environmental problems (Moore et al. 2003), where one of the most

Correspondence: Zhiyun Ouyang. State Key Lab of Systems Ecology, Research Center for Eco-Environmental Sciences, Chinese Academy of Sciences, P.O. BOX 2871, Beijing 100085, China. Email: zyouyang@mail.rcees.ac.cn 
important problems is solid waste (Tinmaz and Demir 2005). Related to environmental preservation and population health (Ojeda-Benitez et al 2003), increases in municipal solid waste (MSW) have become a pressing issue for cities throughout the world. In the USA, since 1980, the total annual generation of MSW has increased more than 50\% from its 2003 level (EPA 2003). In Asia, MSW generation in urban areas is estimated to have risen from 0.76 billion to 1.8 million tons per day between 1998 and 2025 (Pokhrel and Viraraghavan 2005). In China, solid wastes were 380 million tons in 1991, and jumped to 800 million tons in 1995 (Cowing and Liu 2003). The increases in MSW generation have resulted in severe soil, atmospheric and water pollution, and many cities are surrounded by solid-waste dumping sites that occupied 50,000 ha of land by the end of 1998 (Dong et al. 2001). Throughout the world, over 200 cities are surrounded by MSW (China's Agenda 21 1994). The greenhouse gas, methane $\left(\mathrm{CH}_{4}\right)$, odorous volatile gases, fly ash, ethane and other gaseous hydrocarbons emitted from solid-waste disposal sites, can be detrimental to local and global air quality (Khali 2000; IPCC 1996; Decker et al. 2000; Hurst et al. 2005; Bradley et al. 2001; Allen et al. 1997). For example, $\mathrm{CH}_{4}$ released from landfill accounts for 6-18\% of total $\mathrm{CH}_{4}$ released to the atmosphere (Yu 1997). Leakage from landfills impacts soil and underground water quality (Al-Yaqout and Hamoda 2003; Chen and Li 1995; Xu et al. 1999). For example, chemical oxygen demand (COD) from leakage, an indicator of organic pollution, could reach levels as high as $90000 \mathrm{mg} / \mathrm{l}$ (Chen and Li 1995).

The environmental impacts of MSW are mainly as a source of organic pollution, which is closely related to carbon, a structural element in many materials. The environmental problem of MSW is basically the result of imbalance in carbon metabolism of urban ecosystems. Carbon in solid wastes is originally captured from the atmosphere and lithosphere. As economic activities expand, solid wastes continue to exceed nature's absorption ability and carbon metabolism is impaired. Consequently, MSW carbon discharge has already imposed a remarkable load on our environment Studies on MSW carbon discharge are not only an important component in analysis of carbon metabolism in urban ecosystems, but also provide methods to assess the environmental pressure of
MSW and contribute to plans for sustainable urban development.

Few studies have considered carbon metabolism in urban ecosystems. Most research on solid waste has been focused on waste generation and composition analysis, estimation of methane and carbon dioxide emissions from landfill, and related policy implication in waste management; however, overall estimates of MSW carbon discharge are rare. This paper estimated MSW carbon discharge for Haikou City in China, from the viewpoint of the materials cycle. As most MSW in Haikou is disposed of in landfill, with little recycling, the amount of carbon that would be emitted as methane under landfill conditions was also estimated. Finally, to find the relationship between MSW carbon discharge and human activities, the trends of MSW carbon discharge and impacting factors have been analysed.

\section{STUDY AREA}

Haikou City is in southern China, with an area of approximately $2000 \mathrm{~km}^{2}$, on the southern bank of the Qiongzhou Strait, facing the Leizhou Peninsula on the mainland. The latitude (N) is $19^{\circ} 32^{\prime}$ to $20^{\circ} 5^{\prime}$, and longitude (E) is $110^{\circ} 10^{\prime}$ to $110^{\circ} 41^{\prime}$. The area has a tropical marine climate, with an annual mean temperature of $23.8^{\circ} \mathrm{C}$ and annual mean rainfall of $1664 \mathrm{~mm}$. The area has long beaches, seaside swimming grounds, excellent sampan racing grounds, and well-preserved volcanic remains. Relying on the pleasant climate and abundant natural resources, Haikou has become a famous tourism city in China. During autumn and winter, Haikou's tourism season peaks due to its climate, which is warmer than other parts of China.

As the capital of Hainan Province, one of five Special Economic Zones (S.E.Z.) in China, Haikou has experienced rapid economic and population growth over the past two decades. In 2003, the permanent residential population was $1,626,411$. With this development, Haikou's MSW has increased. Currently, landfill is the primary garbage disposal measure in Haikou and two landfills (Yanchunlin and Baishuitang) have been built and put into use. Because the city is on an island and surrounded by ocean, solid waste disposal faces land scarcity pressures, and any disposal can greatly impact the surrounding coastal ocean environment. As Hainan Province was nominated as an 'ecological province' by the Chinese government in 1998, 
Haikou's solid waste generation and related environmental problems are worthy of serious attention.

\section{METHODS}

\section{Data sources}

Data for the present estimation of Haikou's MSW carbon discharge and its monthly variation analysis were obtained through field sampling. The sampling sites and programme are described below. Data for the trend analysis of MSW carbon discharge were obtained from solid waste surveys carried out by the Haikou Environment and Sanitation Bureau, including MSW generation and composition from 1991 to 1999. Data for impact factors analysis were collected from the Haikou Statistical Yearbook, including demographic and economic statistics.

\section{Sampling sites and programme}

In Haikou, there are 11 garbage transfer stations (GTS) and two landfills. The 11 garbage transfer stations are mainly in the northeast parts of the city, which are commercial and residential centres. In this study, nine representative garbage transfer stations were selected as sampling sites (Figure 1). These sampling sites occupy $70 \%$ of the total area of all garbage transfer stations in Haikou.

Field sample collections were carried out between August 16 and 18, October 18 and 20, and December 20 and 22. The sampling periods were determined according to the seasonal variation in tourism, because Haikou has little seasonal temperature variation. Near the National Day (October 1) and Spring Festival (Lunar New Year), Haikou has its high tourism season because of the festivals and the warmer temperatures.

The solid wastes, sampled from containers in each garbage transfer station, were unloaded in open and clear ground, because waste characterisation was largely determined by field-scale analyses of waste (Esra et al. 2005). The samples were then mixed and raked into quarters, and two diagonal sections were taken out and weighed. If the weight of each part was more than $90 \mathrm{~kg}$, they were mixed again and the quartering procedures were repeated (Nie 2000). One of the two parts was taken as a representative sample of less than $90 \mathrm{~kg}$ (Nie 2000). The samples were separated into their components and each component was weighed. Hand sorting was used for waste component classification. To obtain the dry weight of the components, the representative samples were dried at $105^{\circ} \mathrm{C}$ and weighed

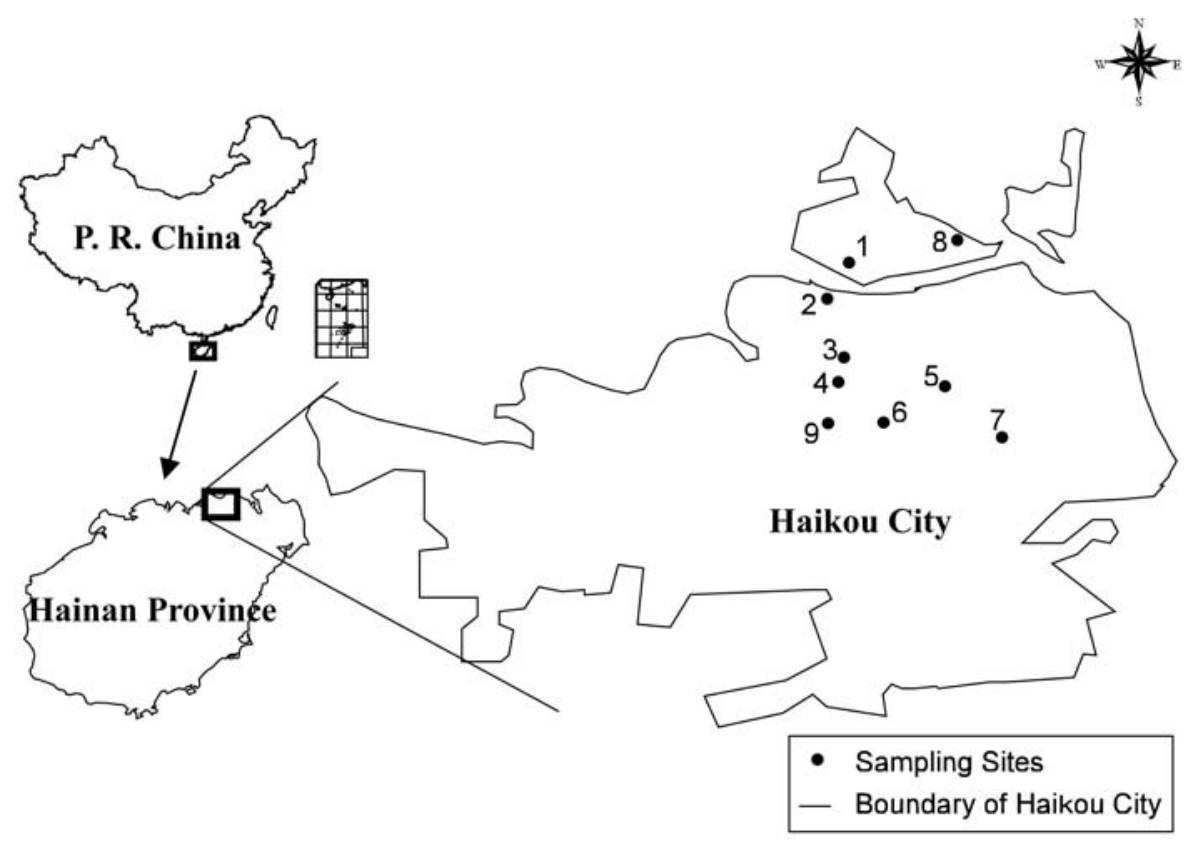

Figure 1 Distribution of sampling sites in Haikou City. 1, Haidian 2 West Road; 2, Binhai Road; 3, Bazhao; 4, Yizhong; 5, near the Science Center in Haifu Road; 6, Daying Market; 7, Longqi in Haifu Road; 8, Haidian 2 East Road; 9, Longhua Road 
again. Given the wet and dry weights of each component, we obtained the water content of MSW, which is fundamental for the carbon calculation.

\section{Carbon calculation}

The amount of carbon in municipal waste was calculated using formula 1 :

$C_{M S W}=W M S W \times \sum\left(p_{i} \times r_{i}\right)$

where $C_{M S W}($ tons $\mathrm{C} / \mathrm{yr})$ is the amount of carbon in municipal solid waste; WMSW is the wet weight of municipal solid waste discharged annually; $r_{w}$ is the ratio of dry weight to wet weight in garbage, a determinant of water content; $p_{i}$ is the carbon content of component $i$ in dry weight, obtained from Nie (2000); and $r_{i}$ is the ratio of components in dry weights.

The methane carbon emitted from landfills was estimated from formula 2. The amount of carbon emissions was estimated using the default method in formula 3 (Bingemer and Crutzen 1987), as applied in the revised IPCC guidelines (1996), as the default method for estimating methane emissions from solid waste disposal sites (Kumar et al. 2004).

$C_{\mathrm{CH}_{4}}=$ emission $_{\mathrm{CH}_{4}} \times 12 / 16$,

emission $_{\mathrm{CH}_{4}}=\left(M S W_{T} \times M S W_{F} \times M C W \times D O C \times\right.$ $\left.D O C_{F} \times F \times 16 / 12-R\right) \times(1-O X)$

where $C_{C H_{4}}(\mathrm{GgC} / \mathrm{yr})$ is the amount of carbon in methane emitted from landfill; emission ${ }_{C H}(\mathrm{Gg} / \mathrm{yr})$ is the annual $\mathrm{CH}_{4}$ emission from landfill; $M S W$ $(\mathrm{Gg} / \mathrm{yr})$ is annual municipal solid waste generation; $M S W_{F}$ is the fraction of MSW disposed of at the disposal sites, and was assumed to be $100 \%$, provided that landfill received all MSW; $M C W$ is the methane correction factor ( 0.4 for open dumps $<5 \mathrm{~m}$ depth in developing countries) $D O C(\mathrm{Gg} / \mathrm{yr})$ is degradable organic carbon determined from $0.4 A+0.17 B+0.15 C+0.3 D$ (weight ratio: $A=$ paper + rags, $B=$ leaves + hay + straw, $C=$ fruits + vegetables, $D=$ wood); $D O C_{F}$ is the fraction of DOC that is converted to landfill gas (LFG) with a default value of $0.77 ; F$ is the fraction of methane in LFG with a default value of $0.5 ; R$ is recovered methane with a default value of zero; and $O X$ is the oxidation factor and assumed to be zero (default value).

\section{Software for data analysis}

Windows Excel 2000 and SPSS version 10.0 were selected for data analysis. Excel 2000 was applied in data storage, carbon calculation and figure drawing. SPSS 10.0 was applied in descriptive statistics, correlation analysis and stepwise regression.

\section{RESULTS}

\section{The present situation of MSW carbon} discharge

In 2001, Haikou's municipal solid waste generation was $269.1 \mathrm{Gg} / \mathrm{yr}$, with an average annual per capita of $447 \mathrm{~kg} / \mathrm{yr}$. This was comprised of: food scraps $(26 \%)$, dust and stone $(16 \%)$, wood $(12 \%)$, fabrics $(12 \%)$, paper $(11 \%)$, plastics $(10 \%)$, and glass $(13 \%)$. Food scraps are the primary component in Haikou's MSW.

With this MSW generation, carbon discharge through municipal solid waste in Haikou was $105.1 \mathrm{GgC}$ in 2001 , with an average annual per capita of $174.6 \mathrm{kgC} / \mathrm{yr}$. If landfills received all of this waste, $4.7 \%$ of MSW carbon would become $\mathrm{CH}_{4}$, with a value of $4.9 \mathrm{GgC}$ or $8.1 \mathrm{kgC}$ per capita. Carbon in landfills is released from food scraps (24\%), plastics $(20 \%)$, wood $(17 \%)$, fabrics $(14 \%)$, paper $(13 \%)$, and dust and stone $(12 \%)$. Food scraps and plastics are the most important sources of MSW carbon discharge. Although the weight of plastics was not high, plastics carbon had the second highest carbon content. Carbon from glass is small, although the weight ratio of glass in MSW is $13 \%$.

\section{Monthly variation in MSW carbon discharge}

Because of the lack of monthly statistics for MSW generation, here we only discuss the monthly variation in MSW carbon content. In October and December, MSW carbon content was higher than that in August (Figure 2). Temperature varies little in Haikou, where average temperature from 1992 to 1999 in August was $28^{\circ} \mathrm{C}$, and $22.5^{\circ} \mathrm{C}$ in October and December. However, because of the traditional holidays, the high tourism seasons in October and December bring many tourists to the island city: 361,000 in December and 317,000 in August. The high carbon content of MSW in October and December is probably the result of peaks in 
tourism. In the high season, many plastics and food scraps are discharged, and their overall weight ratio in MSW may increase, leading to an increase in the carbon content of MSW because the carbon content of plastics and food scraps is higher than in organic components, such as glass.

\section{Annual variation in MSW carbon} discharge

As shown in Figure 4, annual per capita MSW carbon discharge increased from 133.1 to

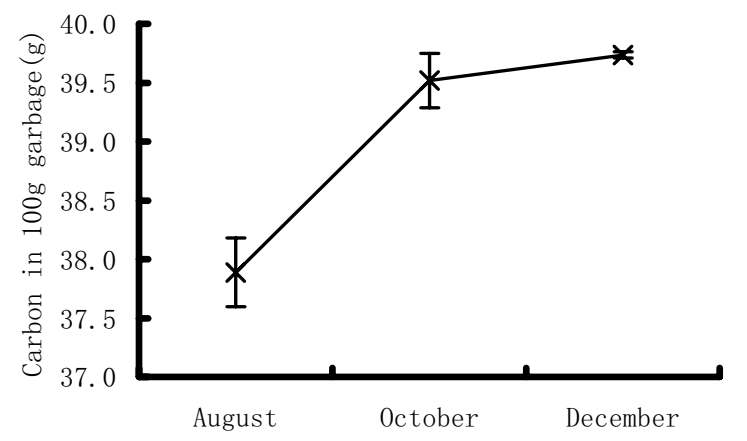

Figure 2 Monthly changes in MSW carbon content in Haikou
$212.9 \mathrm{kgC} / \mathrm{yr}$ between 1991 and 1999, a rate of $59.9 \%$. The ratio increased 1.6 fold between 1991-1993, compared with a 1.0-fold increase in the following six years, from 1993 to 1999.

In line with population growth, the total annual MSW carbon discharge increased 124.9\% from 1991 to 1999 (Figure 4). In 1999 the total MSW carbon discharge was $115.8 \mathrm{GgC} / \mathrm{yr}, 2.2$ times as large as in 1991. However, the average per capita MSW carbon discharge in 1999 was only 1.9 times as large as that in 1991. Similar to per capita MSW carbon discharge, the total MSW carbon discharge increased 1.8-fold between 1991 and 1993, and 1.3-fold between 1993 and 1999. With the increase in MSW carbon discharge, $\mathrm{CH}_{4}$ emission also increased $135.2 \%$ between 1991 and 1999, and the percentage of methane emission varied from $3.7 \%$ to $4.1 \%$, with a mean of $3.9 \%$.

\section{Factors influencing MSW carbon} discharge

Drawing from various studies, it can be reasonably asserted that the generation and composition of

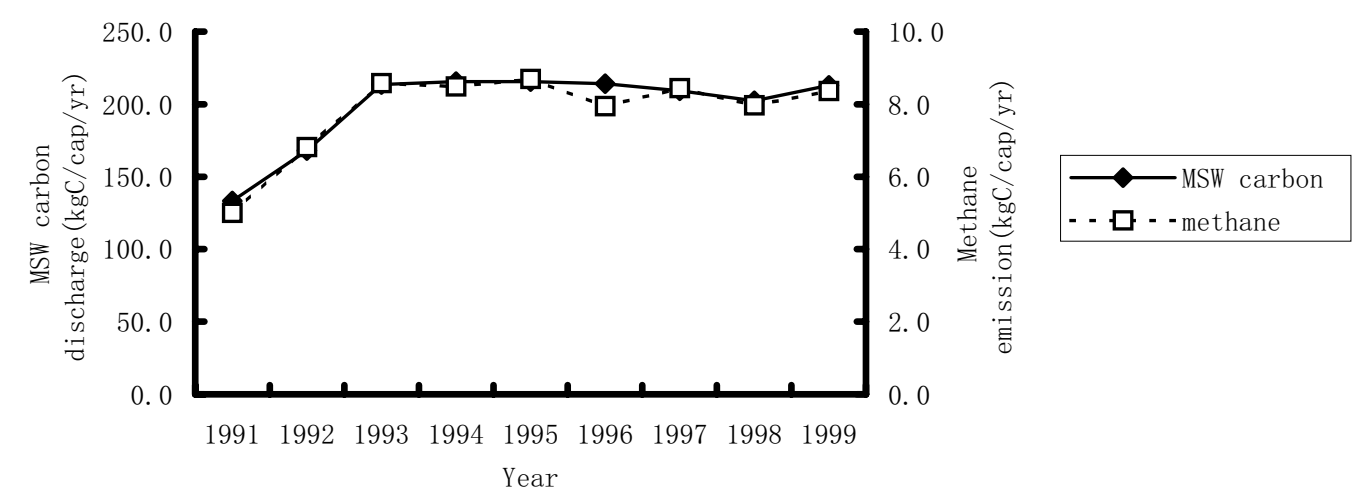

Figure 3 Annual variation in per capita MSW carbon discharge between 1991 and 1999

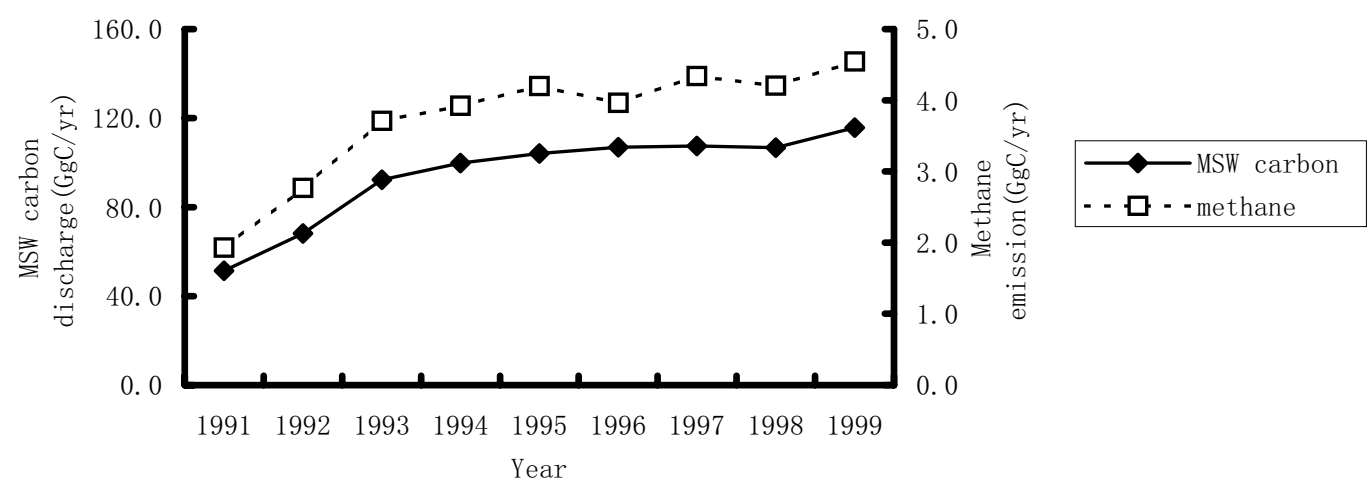

Figure 4 Annual variation in MSW carbon discharge between 1991 and 1999 

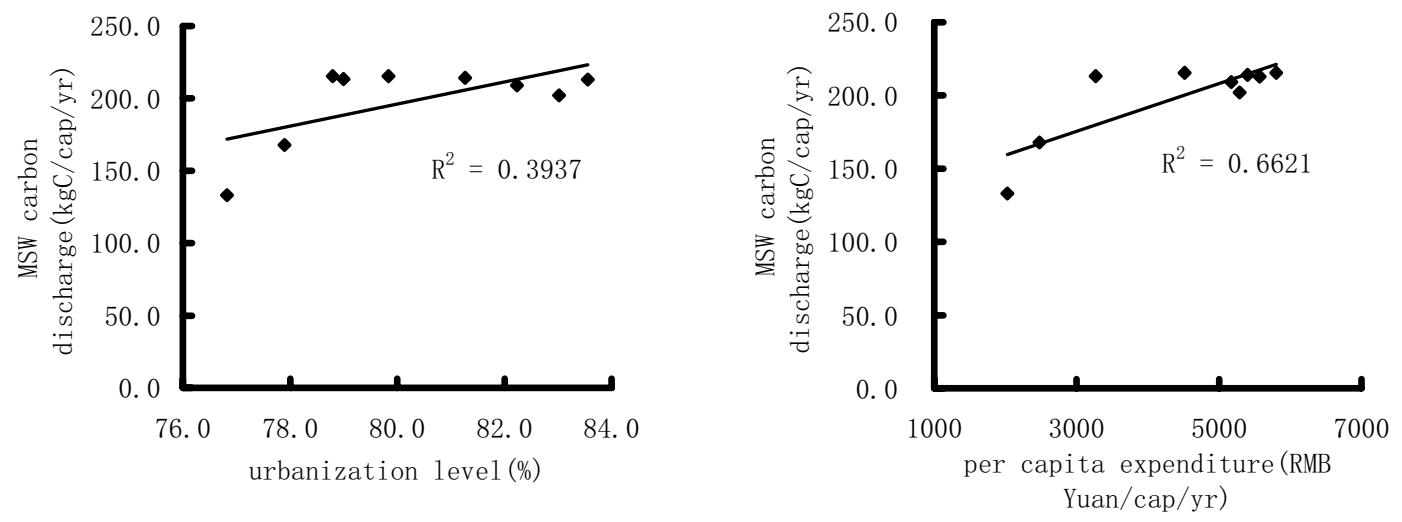

Figure 5 Relationship between MSW carbon discharge, urbanisation (left) and expenditure (right)

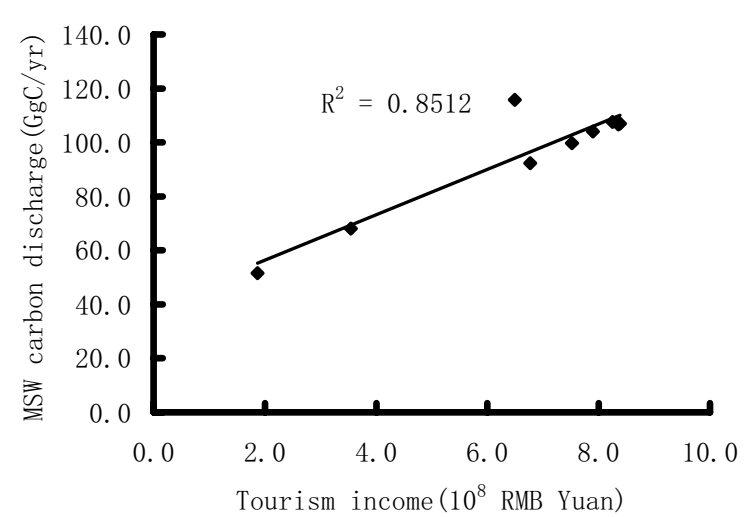

Figure 6 Relationship between MSW carbon discharge and tourism income

municipal solid wastes are related to demographic and socio-economic factors, such as population, economic status and resident lifestyle (Mosler et al. 2005; Jiang et al. 2003). Here, we examined whether there is relationship between demographic and socio-economic factors and MSW carbon discharge and the nature of any relationship.

Per capita annual MSW carbon discharge increased significantly $(p=0.10)$ with urbanisation (urban population/total population), and per capita expenditure (Figure 5). After stepwise regression analysis, we obtained the formula $y=126.464+(1.634 E-0.2) x$, where $y$ is per capita annual MSW carbon discharge $(\mathrm{kgC} / \mathrm{yr}), x$ is per capita annual expenditure (RMB Yuan/yr, US $\$ 1.0=8.0$ RMB Yuan), significance is 0.008 , and $x$ explains $66.2 \%$ of data. Therefore, compared with urbanisation levels, residents' expenditure status has a much greater impact on MSW carbon discharge.

Besides general socio-economic factors, the local features of tourism may also impact MSW carbon discharge, as Haikou is a typical tourism city. From analysis of monthly variations in MSW carbon discharge, we see the influence of tourism, which was confirmed by the highly significant relationship between MSW carbon discharge and income from tourism (Figure 6).

\section{DISCUSSION AND CONCLUSIONS}

Estimation of MSW carbon discharge sheds light on the assessment of solid waste environmental load from the perspective of the carbon cycle. MSW generation in Haikou amounted to $105.1 \mathrm{GgC}$ discharged, which was originally transferred from natural resources. This carbon discharge reflects the environmental burden of MSW. The composition analysis of carbon discharge also provided a baseline for prioritising local MSW reduction measures. For example, recycling policies could be implemented as $47 \%$ of MSW carbon is discharged in the form of recyclable ingredients, including plastics, paper, fabrics and glass, so nearly half of MSW carbon could be returned to urban ecosystems and its environmental impacts could be significantly reduced.

Carbon discharge of MSW is determined by MSW generation and composition, which will increase with the increase in MSW generation and carbon content. Haikou's MSW generation in 2003 was $269.1 \mathrm{Gg}$ per year, or $737.3 \mathrm{t} /$ day, which is much less than megacities in China or other countries. For instance, MSW generation is 12,000 t/day in Shanghai, $13,000 \mathrm{t} /$ day in New York, 20,360 t/day in Los Angeles and 66,000 t/day in Tokyo. Large MSW generation implies large MSW carbon discharge, and thus a large environmental load. In terms of MSW composition, Haikou is 
similar to other large cities in China, in which food scraps are a major component of MSW. However, in some cities in developed countries, paper is a major component and the weight ratio of food scraps is comparatively lower. In Kitakyushu in Japan, paper accounts for $40.1 \%$ of MSW and food scraps were $10.7 \%$ of MSW (Sakai 1996). In Canada, Sweden, the USA and Japan, the average weight ratio of paper exceeded 30\% (Sakai et al. 1996). The lower weight ratio of food scraps in these countries may be related to advanced food technology and dissimilar lifestyles, which may result in different carbon contents. However, cities with large MSW generation are much more likely to have large MSW carbon discharge. Nevertheless, the differences in MSW composition may have different policy implications. For example, the high weight ratio of paper in developed countries' MSW implies that paper recycling and reusing should be given more attention for reducing MSW carbon discharge.

The environmental impacts of MSW carbon discharge differ with disposal methods. In landfills, $\mathrm{CH}_{4}$ emission and leachate pollution are considered the main environmental influences for MSW carbon discharge. With incineration the main influences are emission of polychlorinated dibenzop-dioxin and polychlorinated dibenzofuran ( $\mathrm{PCDD} / \mathrm{Fs}), \mathrm{CO}_{2}, \mathrm{CO}$ and fly ash. While with composting, the major environmental factor is land occupation. Analysing how MSW carbon flows in different disposal methods could help to quantitatively assess the environmental impacts of MSW carbon discharge. In China, landfill is a major solid waste disposal method and the amount of MSW treated in this way is $70 \%$ of the total MSW (Nie and Dong 1998; Zhang 1998). In the case of Haikou, we can see that only $4.7 \%$ of MSW carbon would be emitted as methane from disposal sites. It is possible that a large percentage of MSW carbon in Haikou may be retained in landfills or released into under ground water. As Marxsen (2001) asserted, under landfill conditions, the average amount of carbon sequestered per ton of wet garbage is 0.16 tons. Based on 269.1 Gg of MSW generation, sequestration of $43.1 \mathrm{GgC}$ seems possible if landfills received all municipal solid waste. The proportion of carbon sequestration in the total MSW carbon discharge would reach a high value at $41 \%$, but about $50 \%$ of MSW carbon would flow into leakage as carbonaceous materials. This large proportion of MSW carbon lost through leakage will influence soil and underground water quality, so controlling leakage should be strengthened. Although little MSW carbon would be transferred into methane, methane emissions from landfill impact global warming. Apart from China, over $80 \%$ of MSW in the USA, UK, Canada, Portugal, Finland and Ireland goes to landfill (Clarke et al. 1999). The pattern of MSW carbon flow in disposal sites in these countries may be similar to Haikou. This analysis provides fundamental information for MSW carbon flow under landfill conditions, and contributes to the understanding of human impacts on the carbon cycle. MSW carbon flow for incineration or composting will be analyzed when corresponding data are available. Currently, in Japan, Switzerland, Denmark and Luxembourg, MSW is mainly treated through incineration (Clarke et al. 1999; Sakai 1996). MSW carbon flow from incineration in these and other countries should be considered urgently.

Annual per capita MSW carbon discharge increased significantly with the increase in per capita living expenditure. From the perspective of the carbon cycle, the environmental load of MSW discharge, including methane release, may seriously increase with increasing living standards. The relationship between MSW carbon discharge and living expenditure can be seen from a comparison of Madras and Haikou. Appasamy and Lundquist (1993) estimated that MSW carbon discharge in Madras was 482 tons/day in 1992, or an annual per capita carbon discharge of $46.4 \mathrm{kgC} / \mathrm{yr}$, which is lower than in Haikou. Comparing the economic status of these two cities, Madras per capita living expenditure in 1992 was apparently lower than that of Haikou in 2003 (Perera 1993; Editorial Committee of Statistics in Haikou 2004). Such a relationship signals an alarm as to the anthropogenic impacts of MSW discharge. At present in developing countries, living expenditure is synchronised with the process of rapid growth, and may lead to an increase of MSW carbon discharge, if recycling measures are insufficient. In developed countries, living expenditure is high, with a highconsumption lifestyle, and MSW carbon discharge may be more serious than in developing countries. Fortunately, the recycling ratio of MSW in developed countries is comparatively high: $22 \%$ in Switzerland, $19 \%$ in Denmark and $16 \%$ in Sweden and the Netherlands. Nevertheless, large MSW carbon discharge is more likely to occur together with economic development. Disposal technology 
improvements to reduce the environmental impacts of MSW carbon discharge, and 3R measures (recycle, reuse and reduce) to reduce MSW carbon discharge should be adopted. Based on the relationship between per capita MSW carbon discharge and per capita living expenditure in China of $y=126.464+(1.634 E-0.2) x(y:$ MSW carbon discharge per capita; $x$ : living expenditure per capita), we have estimated average annual per capita MSW carbon discharge as $264.9 \mathrm{kgC} / \mathrm{yr}$, with an average per capita expenditure of 8472 RMB Yuan. Though this estimation is not absolutely accurate, it provides an insight into the average level of MSW carbon discharge in China's cities.

The analysis also shows that, as a typical tourism city, Haikou's MSW carbon discharge is heavily influenced by tourism activities. MSW management in tourism cities needs greater attention, especially during peak tourism periods. Previous literature also shows the same relationship between MSW generation and tourism activities (Santos et al. 2005; Gidarakos et al. 2005; Kuniyal et al. 1998).

From the above discussion, we can see that, although this is only a pilot analysis for a typical city in China, it provides some insights into MSW in similar cities. Increases in MSW, based on income, imply that MSW carbon discharge will play an increasingly significant role in sustainable development. Further, because MSW carbon discharge is a part of carbon metabolism at both local and global scales, integrating carbon discharge with carbon consumption will give a systematic overview of carbon metabolism, and provide further insights into the generation mechanisms of urban environmental pollution.

\section{ACKNOWLEDGEMENTS}

We greatly appreciate the assistance of Dr. Andres Vina of Michigan State University and Dr. Erich Schienke of Rensselaer Polytechnic Institute in providing many suggestions. This study was funded through the knowledge innovation project of the Chinese Academy of Sciences (KZCX2-YW-422) and the National Basic Research Program of China (2005 CB 724206).

\section{REFERENCES}

Allen MR, Braithwaite A and Hills CC. Trace organic compounds in landfill gas at seven U.K. waste disposal sites. Environmental Science E Technology 1997;31:1054-61

$\mathrm{Al}$-Yaqout AF and Hamoda MF. Evaluation of landfill leachate in arid climate - a case study. Environmental International 2003;29:593-600

Appasamy P and Lundqvist J. Strategy of water supply and waste disposal in Madras. Ambio 1993;22(7): 442-8

Bingemer $\mathrm{HQ}$ and Crutzen PJ. Production of methane from solid waste. Journal of Geophysical Research 1987;87(D2):2181-7

Bradley AD, Cook DJ, Edwards JS, Johnston AG Linforth RS and Taylor AJ. The control and measurement of landfill odours. Proceedings of Eighth International Landfill Symposium, Sardinia; 2001: 681-90

Chen YC and Li ZP. Controlling the pollution of extravasate from urban municipal solid waste. Environmental Science Trends 1995;4:15-18 (in Chinese)

China's Agenda 21. White Paper on China's Population, Environment and Development in the 21st

Century. http://sdep.cei.gov.cn/baipishu/ cchnwp19.htm; 1994

Clarke MJ, Read AD and Phillips PS. Integrated waste management planning and decision-making in New York City. Resources, Conservation and Recycling 1999;26(2):125-41

Cowing MJ and Liu YS. Capacity Development for Municipal Solid Waste in China. United Nations Development Programme. Report of the Evaluation Mission. http://www.undp.org.cn/cpd/ EvaluationRpt_MunicipalSolidWaste.pdf; 2003

Crane P and Kinzig A. Nature in the metropolis. Science 2005;308:1225

Decker EH, Elliott S, Smith FA, Blake DR and Rowland FS. Energy and material flow through the urban ecosystem. Annual Review of Energy Environment 2000;25:685-740

Dong SC, Kurt WT and Wu PY. Municipal solid waste management in China: using commercial management to solve a growing problem. Utilities Policy 2001;10:7-11

Editorial Committee of Statistics in Haikou. Statistical Yearbook of Haikou. Beijing: China Statistics Press; 2004 
Gelbard A, Haub C and Kent M. World population beyond six billion. Population Bulletin 1999; $54(1): 3-40$

Gidarakos E, Havas G and Ntzamilis P. Municipal solid waste composition determination supporting the integrated solid waste management system in the island of Crete. Waste Management 2005; October 3

Hurst C, Longhurst P, Pollard S, Smith R, Jefferson B and Gronow J. Assessment of municipal solid waste compost as a daily cover material for odour contro at landfill sites. Environmental Pollution 2005, $135(1): 171-7$

Intergovernmental Panel on Climate Change (IPCC) Report of the Intergovernmental Panel on Climate Change, Mexico City. 1996; September: 11-13

Jiang Y, Kang M, Liu Z and Zhou YF. Urban garbage disposal and management in China. Journal of Environmental Sciences 2003;15(4):531-40

Khalil MAK. Atmospheric methane: an introduction. In Khalil M (ed.), Atmospheric methane: its role in the global environment. Springer-Verlag, New York; 2000:1-8

Kumar S, Gaikwad SA, Shekdar AV, Kshirsagar PS and Singh RN. Estimation method for nationa methane emission from solid waste landfills. Atmospheric Environment 2004;38(21):3481-7

Kuniyal JC, Jain AP and Shannigrahi AS. Public involvement in solid waste management in Himalavan trails in and around the valley of flowers. Resources, Conservation and Recycling 1998;24: 299-322

Lawrence RJ. Urban health: An ecological perspective. Reviews on Environmental Health 1999;14(1): $1-10$

Marxsen CS. Potential world garbage and waste carbon sequestration. Environmental Science E Policy 2001:4:293-300

Moore M, Gould P and Keary BS. 2003. Global urbanization and impact on health. International Journa of Hygiene and Environmental Health 2003;206 (4-5) :269-78

Mosler HJ, Drescher S, Zurbrugg C, Rodriguez TC and Miranda OG. Formulating waste management strategies based on waste management practices of households in Santiago de Cuba, Cuba. Habita International 2005; Available online 14 November

Nie YF and Dong BC. Solid waste management and minimization in China. Environment Protection 1998;2:6-9
Nie YF. Engineering and Technological Handbook of Three Waste disposal: volume of solid wastes. Beijing: Chemical Industry Press; 2000

Ojeda-Benitez S, Armijo de Vege C and RamirezBarreto ME. Characterization and quantification of household solid wastes in a Mexican city. Resources, Conservation and Recycling 2003;39(3): 211-22

Perera J. Urban livelihood and environmental impacts: a case study on material flow through Madras. Ambio 1993;22(7):460

Pokhrel D and Viraraghavan T. Municipal solid waste management in Nepal: practices and challenges. Waste Management 2005;25 (5):555-62

Sakai S. Municipal solid waste management in Japan. Waste Management 1996;16(5/6):395-405

Sakai S, Sawell SE, Chandler AJ, Eighmy TT, Kosson DS, Vehlow J, van der Sloot HA, Hartlen J and Hjelmar O. World trends in municipal solid waste management. Waste Management 1996;16(5/6): $341-50$

Santos IR, Friedrich AC, Wallner-Kersanach M and Fillmann G. Influences of socio-economic characteristics of beach users on litter generation. Ocean $\mathcal{E}$ Coastal Management 2005;48:742-52

Satterthwaite D. Will most people live in cities? British Medical Journal 2000;321:1143-5

Tinmaz E and Demir I. Research on solid waste management system: To improve existing situation in Corlu town of Turkey. Waste management 2005;8(1):799-810

United Nations Population Division. World Urbanization Prospects: The 1999 revision. New York: United Nations Population Division; 2002

United States Environmental Protection Agency. Municipal solid waste generation, recycling, and disposal in the United States: Facts and figures for 2003. http:/ /www.epa.gov/msw/pubs/msw05rpt.pdf; 2003

Vlahov D and Galea S. Urban health: A new discipline. The Lancet 2003;362:1091-2

Xu C, Yang JX and Wang RS. Life cycle assessment of municipal solid waste in Guanghan city. Journal of Environmental Sciences 1999;19(6):631-5

$\mathrm{Yu}$ GT. Methane released during incinerating garbage. Proceeding in Environmental Science 1997; 5(2):57-64 (in Chinese)

Zhang WC. Situation and management of urban domestic refuse in China. Environment Protection 1998;8:41-3 